\title{
Etiology, Outcome and Mortality Risk Factors in Children Burn
}

\author{
Hamid Karimi ${ }^{*}$, Seyed Abbas Motevalian², Mahnoush Momeni³ ${ }^{3}$ Roya Safari ${ }^{4}$, \\ Mitra Ghadarjani ${ }^{5}$ \\ ${ }^{1}$ Faculty of Medicine, Iran University of Medical Sciences, Tehran, Iran \\ ${ }^{2}$ Faculty of Health School, Iran University of Medical Sciences, Tehran, Iran \\ ${ }^{3}$ Faculty of Medicine, Iran University of Medical Sciences, Tehran, Iran \\ ${ }^{4}$ Department of Biostatistics and Epidemiology, Faculty of Health School, Kerman University of Medical \\ Sciences, Kerman, Iran \\ ${ }^{5}$ Emergency Department, Motahary Burn Hospital, Iran University of Medical Sciences, Tehran, Iran \\ Email: $\underline{\text { hamidkarimi1381@yahoo.com, }}$ karimihamid11@gmail.com
}

Received 7 January 2015; accepted 7 February 2015; published 10 February 2015

Copyright (C) 2015 by authors and Scientific Research Publishing Inc.

This work is licensed under the Creative Commons Attribution International License (CC BY). http://creativecommons.org/licenses/by/4.0/

(c) (i) Open Access

\begin{abstract}
Mortality rate of burn patients can serve as an objective criterion for quality control and as a measure for research and preventive programs. A prospective study of burn victims, from data of burn registry program, was conducted to determine the etiology, risk factors of mortality and outcome of pediatric burns. We had 514 patients below 15 years old. Burns caused by scalding were the most frequent (55.4\%) followed by flames (35.8\%). Mean (SD) of age was 3.72 (3.19) years. Male to female ratio was 1.62:1. Mean hospital stay was 14.17 days (range 0 - 46 days). The mean TBSA (SD) was $15.22 \%(14.31 \%)$. Fifty three patients had inhalation injury $(11.25 \%)$. Inhalation injury increases the risk of death (Odds Ratio: $8.75, p=0.009)$. Length of stay increased in accordance with burn area $(p<0.002)$. Burn wound infection was present in $(35.4 \%)$ of our patients. The univariate statistics analysis and a pooled, cross-sectional, multivariate logistic regression were done. The major risk factors were: Inhalation injury $(O R=8.75, p=0.009)$ and lack of intra-venous fluid resuscitation before reaching the hospital ( $O R=40.5 \%, p=0.001)$, cause of burn (flame and chemical) and referral cases from other centers $(O R=3.66, p<0.0001)$. The minor risk factor was age. About $83 \%$ of our patients discharged with partial recovery, $10 \%$ with complete recovery, $0.1 \%$ referred to other hospitals and $1.36 \%$ died.
\end{abstract}

\section{Keywords}

Burns, Risk Factors, Mortality, Registry, Inhalation Injury

${ }^{*}$ Corresponding author. 


\section{Introduction}

Burn injuries are one of the most common causes of injuries in our country.

And in children, it is the $7^{\text {th }}$ cause of disease burden of injuries. Burn injuries have one of the highest mortality rates among trauma injuries in Iran. It is the $13^{\text {th }}$ cause of death and disability-adjusted life years (DALY).

Epidemiological studies of burn injuries can highlight the risk factors of the mortality in burns, and can serve as objective end points for studies, researches and quality control programs.

Calculating and evaluating the mortality rates is the first step in evaluation of outcome of burn, in evaluating the different modes of treatment and in establishment of protocols and guidelines of burn treatment for burn centers [1].

Identification and definition of risk factors that may lead to mortality and morbidity among the pediatric burn patients can help preventive programs in predicting the outcome of the patients, and can help developing more effective programs and conducting more effective measures to prevent the burns. In this regard training of parents and teachers and school staff is very important and cost-effective.

The outcome measures are the first step in evaluating consequences of trauma and the results of health care.

The risk factors of death have changed during the past 40 years. In developed world overall mortality rates following burns have decreased to $5 \%-6.5 \%$. Burn injuries affects $1 \%$ of the population each year and about $10 \%$ of burn injuries are admitted to burn hospitals [2].

But in developing world the frequency of pediatric burns is still high with high frequency of morbidity that would persist through out their life [3].

According to WHO reports, in low income societies burn death rates are eleven times more frequent than in the high income countries [3].

Also according to the literature, age, TBSA (Total body surface area), and inhalation injury are the major risk factors of burn mortality.

In this paper we were to find outcome and major and minor risk factors for death of burn patients in children up to 15 years old.

\section{Material \& Methods}

During 2 years, we had 1721 burn patients of whom 514 were below 15 years old of age.

We used the data of our burn registry program. Data were collected prospectively in our registry program.

All of factors that may lead to mortality and morbidity of our patients were studied. such as age, sex, inhalation injury, the length of time from injury to medical care or hospital, accompanying traumas, previous medical history and illnesses, and place of burn, presence or absence of parents (unsupervised children), anatomic distribution of burn, seasonal variation, cause of burn, extent of burns, burn due to explosion, ignition of clothing, mode of extinguishing the fire, extend of $3^{\text {rd }} \& 4^{\text {th }}$ degree burn, previous clinical condition, any treatment for burn at home, medical staff pre-hospital care, serum therapy before hospital, ICU admission and its mortality, length of hospital stay, mode of therapy and operative intervention, infection, SIRS, sepsis, multiple organ failure, culture of burn wounds, Antibiotics that were used, result of treatment, Lab tests, outcome, mortality rate and cause of death.

We divided the patients according to TBSA: $0 \%-10 \%, 10 \%-20 \%, 20 \%-40 \%$ and $>40 \%$.

These children were categorized into five groups, the infants ( 0 - 1 year), toddlers ( 1 - 2 years), early childhood ( 2 - 6 years), primary school (6 - 10 years) and secondary school child (10 - 14 years).

As in our registry program, inhalation injury was defined on the basis of exposure to smoke, burn in a closed space, presence of carbonaceous sputum, signs of airway obstruction, deterioration of Po2 in serial Arterial Blood gas tests and/or positive findings in bronchoscopy.

Similarly SIRS defined as body temperature $>38$ or $<36$ C, heart Rate $>90 /$ minute, respiratory rate $>$ $20 /$ minute and white blood cell $>12,000$ or $<4000$.

Sepsis defined as systemic inflammation response to infection and positive blood culture. Wound Cultures with more than 100,000 bacteria in each gram of tissue were considered positive.

Multiple organ failure was defined by dysfunction of more than one organ system despite organ support.

We calculate the Odds Ratio (OR) and Adjusted OR for each of variables (univariate and multivariate) that might contribute in patients' mortality.

All of information and Data were collected in a special questionnaire and Data and statistical analysis were 
performed with SPSS 16 software.

$\mathrm{P}$ value less than $0.05 \%$ was considered significant.

\section{Results}

During 2 years we have admitted 1721 patients and 514 of them were children, aged less than 15 years old.

The causes of burn, age groups and patients' sex are presented in Table 1.

Burns caused by scalding were the most frequent (55.4\%) followed by flames (35.8\%). Flame burn was more frequent in age group 6 - 10 years and 10 - 14 years old.

Mean hospital stay was 14.17 days (range 0 - 46 days).

The probability of death was $1.36 \%$.

Male to female ratio was 1.62:1 $($ male $=318$, female $=196)$ as listed in Table 1.

The greatest number of pediatric burn patients was in the age group 2 - 6 years old (44.16\%) and second number was in age group 1 - 2 years old (25.29\%).

The mean age (SD) of the children was 3.72(3.19) years (range: one month - 15 years).

The median hospitalization stay $($ LOS) was 10 days (S.D. $=9.2$, mean $=14.17)($ Table 2$)$.

Length of stay increased in accordance with burn area $(\mathrm{p}<0.002)$.

We had 11 cases of explosion of firework and explosive materials of which 2 cases died due to extend of trauma and extend of burn.

Fifty three children had inhalation injury (11.25\%). Forty six patients had burn in a closed space and 7 patients (13.2\%) were in open space.

Twenty one cases of inhalation injuries were due to propane gas explosion.

Among patients who had inhalation injury, 3 patients died (5.6\%), but in patients without inhalation injury (461 cases), 4 patients died $(0.8 \%)$. The difference is highly significant $(\mathrm{p}=0.0001)$.

The latter 4 patients died due to high extend of burn and/or developing infection and sepsis.

Inhalation injury increase the risk of death, $\mathrm{OR}=8.75, \mathrm{p}=0.009$.

No cases of renal failure and need for renal hemodialysis were reported.

Operative (split-thickness) skin graft was done in 318 (68.53\%) of our patients.

Table 1. Comparison of cause of burns and sex of children in different age groups.

\begin{tabular}{ccccccccc}
\hline \multirow{2}{*}{ Age group } & \multirow{2}{*}{ Total } & \multicolumn{2}{c}{ Gender } & \multicolumn{5}{c}{ Cause } \\
\cline { 3 - 9 } & & Male & Female & Scaled & Flame & Contact & Electrical & Chemical \\
\hline Less than one year & $35(6.81)$ & $18(5.66)$ & $17(8.67)$ & $17(94.44)$ & $1(5.56)$ & 0 & 0 & 0 \\
$\mathbf{1}$ - 2 years & $130(25.29)$ & $88(27.67)$ & $42(21.43)$ & $58(77.33)$ & $10(13.33)$ & $2(2.67)$ & $1(1.33)$ & $4(5.33)$ \\
$\mathbf{2}$ - $\mathbf{6}$ years & $227(44.16)$ & $122(38.36)$ & $105(53.57)$ & $79(59.40)$ & $44(33.08)$ & $1(0.75)$ & $2(1.50)$ & $7(5.26)$ \\
$\mathbf{6}$ - 10 years & $79(15.37)$ & $57(17.92)$ & $22(11.22)$ & $15(29.41)$ & $30(58.82)$ & 0 & $5(9.80)$ & $1(1.96)$ \\
$\mathbf{1 0}$ - 14 years & $43(8.37)$ & $33(10.38)$ & $10(5.10)$ & $3(9.90)$ & $26(78.79)$ & 0 & $4(12.12)$ & 0 \\
$\quad$ Total & 514 & 318 & 196 & & & & & \\
\hline
\end{tabular}

Table 2. The number of patients, mean age, mean TBSA, number of patients with Inhalation injury, number of death and Mean hospital stay.

Number of patients

Mean age

Mean TBSA

Number of inhalation injury

Number of death

Mean hospital stay

\section{4}

3.72 years

$15.22 \%$

53

7

14.17 days 
In our patients 477 cases developed objective signs of infection in Burn wound.

And burn wound biopsy and culture were done for them. 182 patients (out of 477) had positive culture results (38.1\%) (35.4\% of all patients).

The most frequent Bacteria that were found in burn wound culture were: Coagulase-negative Staphylococcus in $47.06 \%$, Entrococcus $20.59 \%$ and Pseudomonas Aeroginosa in $14.71 \%$. While at the same time period, in adults, the frequency of Entrococcus was about 12.24\%.

The most frequent Antibiotics that were prescribed according to sensitivity tests were: Amikacin 91\%, Ceftazidim 56\%, Meropenem $47.7 \%$.

In the 2 year study period there were 7 in-hospital child deaths due to burn (1.36\%).

Mean (SD) of hospital stay and mean (SD) TBSA of children who survive and children who died is presented in Table 3. The difference was not significant.

The highest mortality rate was in age group 10 - 14 years old (Table 4).

The outcome of patients is shown in Table 5.

The logistic regression analysis showed that previous medical condition, female sex, season of year, site of burn such as "hand" or "head and neck" and depth of burn ( $3^{\text {rd }}$ or $4^{\text {th }}$ degree $)$ had no relation with the mortality of our patients.

But, inhalation injury ( $\mathrm{p}=0.009$ ), cause of burn (flame burn, $\mathrm{p}=0.002$, chemical burn, $\mathrm{p}=0.0001$ ), lack of fluid resuscitation before hospital $(\mathrm{p}=0.001)$ and age $(\mathrm{p}<0.05)$ had positive relation with the patients' death.

And skin Graft surgery $(\mathrm{p}=0.000)$ and taking fluid therapy before reaching to hospital $(\mathrm{p}=0.001)$ had negative relation to the mortality of the patients.

Table 3. Mean hospital stay and mean TBSA in dead and alive pediatric burn patients.

\begin{tabular}{ccccc}
\hline Outcome & Mean hospital stay (SD) & p-value & Mean TBSA (SD) & p-value \\
\hline Dead & $17.67(9.89)$ & 0.193 & $21.67(33.56)$ & 0.665 \\
Alive & $13.55(7.64)$ & & $15.35(12.83)$ & \\
\hline
\end{tabular}

Table 4. The mortality rates in different age groups.

\begin{tabular}{cccc}
\hline \multirow{2}{*}{ Age group } & \multicolumn{2}{c}{ Outcome (freq) } & Probability of death \\
\cline { 2 - 3 } Less than 1 year & Dead & Alive & 0 \\
$\mathbf{1}-\mathbf{2}$ years & 0 & 35 & $1.5 \%$ \\
$\mathbf{2}-\mathbf{6}$ years & 2 & 130 & $1.3 \%$ \\
$\mathbf{6}-\mathbf{1 0}$ years & 3 & 227 & 0 \\
$\mathbf{1 0}-\mathbf{1 4}$ years & 0 & 79 & $4.65 \%$ \\
Total & 2 & 43 & $1.36 \%$ \\
\hline
\end{tabular}

Table 5. Outcome of patients.

\begin{tabular}{|c|c|c|}
\hline Patient condition after discharge & Frequency & Percentage \\
\hline Complete recovery & 56 & $10.8 \%$ \\
\hline Partial recovery (need further treatment and admission) & 431 & $83.8 \%$ \\
\hline Amputation & 0 & $0 \%$ \\
\hline Death & 7 & $1.36 \%$ \\
\hline Referring to other hospitals & 1 & $0.1 \%$ \\
\hline Discharge by patient request (against physician's recommendation ) & 19 & $3.6 \%$ \\
\hline Total & 514 & $100 \%$ \\
\hline
\end{tabular}


The Multiple logistic regression analysis for age, Inhalation injury, flame burn, lack of resuscitation, infection and TBSA was done. And results are shown in Table 6. Multivariated analysis of the prognostic factors shows that Inhalation injury, age, Lack of fluid resuscitation before hospital have positive relationship with mortality of our patients. Odds ratio (OR) for inhalation injury is 8.75 (4.89 - 14.1), lack of fluid resuscitation 40.5 (10.2 51.55) and for age OR = $1.19(1.01-1.7)$.

Referral of patients from other centers had OR $=3.66(1.7$ - 10.2).

\section{Discussion}

Burn injury is one of the most devastating and disabling trauma to human being.

Burn injury remains a serious threat to the well-being of the pediatric population and is still very frequent in our country and other developing countries. It has a high mortality and morbidity rate. During our previous study, it was shown that during four years, the mortality rates in children was $10.6 \%$.and rate of morbidity was about 21\% [4].

Burn still has major cosmetic and functional consequences. In this study we examined the (major and minor) risk factors of mortality in our pediatric patients. And the purpose of the study was to survey the effects of the factors involving in survival of burn victims from the site of injury to the hospital. And to identify those that are major factors of death.

The mortality rate in our country and our center was reported to be significantly higher than the developed countries 2. These Data can help health organizers and authorities to develop measures to decrease the mortality rates of the patients, to design plans for better burn care and better burn care facilities management and to use factors that can reduce the mortality and morbidity of the patients (Table 7).

There are some reports about calculating mortality risk factors of burn patients, such as: Rayan et al. in 1996 have found three risk factors of death in their center. Those factors were age over 60 , TBSA more than $40 \%$ and inhalation injury. And sex was not a risk factor [5].

Coste et al. have developed a predictive formula for predicting death rate. But they did not include the inhalation injury effect [6].

Saffle et al. and Smith et al. have seen the effect of inhalation on mortality rate. They report that $4 \%$ mortality will go to $29.4 \%$ if inhalation injury is present [7] [8]. In our study it was shown that presence of inhalation injury will increase mortality rate several folds.

Table 6. Risk factors.

\begin{tabular}{ccc} 
Risk factor & Odds ratio & p-value \\
\hline TBSA & 1.03 & 0.267 \\
Age & 1.19 & 0.050 \\
Inhalation injury & 8.75 & 0.009 \\
Lack of fluid resuscitation before hospital & 40.5 & 0.001 \\
Length of stay in hospital & 1.05 & 0.182 \\
Time from burn site to hospital & 0.86 & 0.650 \\
Ignition of clothing & 4.69 & 0.061 \\
\hline
\end{tabular}

Table 7. Cause of burn and probability of death.

\begin{tabular}{ccc}
\hline Cause & Freq (\%) & Probability of death \% \\
\hline Scald & $172(55.48)$ & 0 \\
Flame & $111(35.81)$ & 3.03 \\
Contact & $3(0.97)$ & 0 \\
Electrical & $12(3.87)$ & 0 \\
Chemical & $12(3.87)$ & 16.67 \\
\hline
\end{tabular}


Bloemsma et al. reported a mortality rate of 6.9\%. And American National Burn repository reported mortality of $5.6 \%$ [2].

Muller et al. had reported mortality rate of 3.6\% and TBSA, age, presence of inhalation injury and female sex were the risk factors of death [9].

Vico et al. have found the same risk factors [10]. And Benmeir et al. also emphasis on female sex as a major risk factor of death [11]. Muller postulated the difference in the thickness of skin and proportion of body fat to muscle mass may be contributing factor for higher mortality in female sex [9]. Although in these previous reports "female sex" is an important risk factor, in our study this was not found to be risk factor of death!

All of these studies have a low mortality rates, from about $3.6 \%$ to $7 \%$. None of these studies were in pediatric age group [12]-[19].

Moreover reports on risk factors of death in children are rare. From 1993 till present we could find only 13 papers about this issue in the literature [20]-[32].

Wolf et al. have reported the mortality determinant in massive pediatric burns which were TBSA burns equal or more than $80 \%$ and full thickness burns equal or more than $70 \%$ [20].

Regarding TBSA, the admission criteria for children in our center is: $2^{\text {nd }}$ degree burn more than $10 \%$ and/or $3^{\text {rd }}$ degree burn more than $5 \%$. In about $10 \%$ of patients it is possible to do "early excision and skin grafting" in few days. But in others serial dressing + debridment and eventually skin grafing would be the treatment plan of the patients.

During last 10 years our knowledge of inhalation injury and chemical injury increased and effective treatment of them resulted in improvement in survival of our patients.

Toon et al. in 2011, Spinks et al. in 2008 and Thombs et al. in 2006 have reported that higher mortality is between 0 - 4 years old. In our study it was found that "age" has a positive relation with mortality of children, and it is not like previous studies in pediatric burn. Also age that has high probability of death was below 4 years old in previous studies, however in our study the highest morality rate was observed in more than 10 years of age. During this study we found that children within age group 10 - 14 years old have higher probability of death. This is mostly because these children mostly have flame burn (higher risk activities) and have higher TBSA than age group 0 - 4 years old [25] [27] [28] [33].

In this study we found that Mean hospital stay were not different between dead and alive pediatric burn patients. Also mean TBSA were not different between these two groups. It is on the contrary to the report of Light et al. in 2009, they noted that TBSA and length of stay are higher in non-survivors. Also there is a report from Morrow et al. that the mean burn size was significantly larger for non-survivors than survivors [21] [23].

There are some other reports that platelet count, fatty liver and early feeding have influence on survival of children, these issues were not evaluated in our study [29] [31] [32].

In our survey we noted a mortality rate of $1.36 \%$. But Light et al. reported mortality of $10 \%$ in India [21].

We studied the risk factors that may contribute to mortality rate. The major risk factors for death in our pediatric patients were:

Inhalation in jury, lack of fluid therapy before reaching to hospital, cause of burn (Flame and chemical burn ) and referral patients from other hospitals.

The minor risk factors were age.

Referral patients from other centers had $\mathrm{OR}=3.66$. It is because naturally referral patients have more problems and more extensive TBSA that cannot be treated in the primary Hospital. And they may reach to our Hospital with delay.

It is obvious that burn patients are in hypovolemic shock and from the first minute of injury they have to be given aggressive fluid therapy with ringer lactate solution. So if they are given IV fluid during the time of transport from injury site to hospital, the rate of complications and mortality would be lower; thus it shows the importance of "fluid therapy before reaching to hospital".

There were some factors that had not any relation to mortality rate such as site of burn (hand or head \& neck), female sex, full-thickness burns, season of year that burn occurred, previous medical condition, ignition of clothing and accompanying trauma.

These data can help the authorities in "Health and treatment ministry" to predict survival of pediatric burn patients, promote measures to reduce the risk factors of their death, to compare the result of treatments during the previous years with each other and among pediatric burn centers in the country, to provide newer and effective treatment modalities for burn patients, to promote training programs for parents and care givers in the media and 
to evaluate the results of new treatments on pediatric patients.

\section{Conclusions}

Inhalation injury, lack of fluid therapy before reaching to hospital, cause of burn (Flame and chemical burn) and referral patients from other hospitals are major risk factors of death in pediatric burn patients.

Full-thickness burn and female sex, on the contrary to previous reports, has not any influence on pediatric burn death.

\section{Acknowledgements}

The authors wish to thank Mrs. Bita Kamranfar, Mrs. Monireh Milani, Mrs. Akram Kermanshahi and Mrs. Rafat Amiri for their kind and very effective cooperation in conducting the present study.

\section{Declaration}

"None of the authors has a financial interest in any of the products, devices, or drugs mentioned in this manuscript.”

\section{Conflicts of Interest and Source of Funding}

This study has been performed by the fund from Research vise president office, Iran University of Medical Sciences.

There is no conflict of interests among authors.

\section{References}

[1] Lv, K.-Y., Xia, Z.-F., Zhang, L.-M., Jia, Y.-T., Tan, T., Wei, W., Ma, B., Xiong, J., Wang, Y. and Sun, Y. (2008) Epidemiology of Pediatric Burns Requiring Hospitalization in China: A Literature Review of Retrospective Studies. Pediatrics, 122, 132-142. http://dx.doi.org/10.1542/peds.2007-1567

[2] Bloemsma, G.C., Dokter, J., Boxma, H. and Oen, I.M. (2008) Mortality and Causes of Death in a Burn Centre. Burns, 34, 1103-1107. http://dx.doi.org/10.1016/j.burns.2008.02.010

[3] The Global Burden of Disease, 2004 Update; WHO Library Cataloguing-in-Publication Data.

[4] Karimi, H., Montevalian, A., Motabar, A.R., Safari, R., Parvas, M.S. and Vasigh, M. (2012) Epidemiology of Paediatric Burns in Iran. Annals of Burns and Fire Disasters, 25, 115-120.

[5] Ryan, C.M., Schoenfeld, D.A., Thorpe, W.P., Sheridan, R.L., Cassem, E.H. and Tompkins, R.G. (1998) Objective Estimates of the Probability of Death from Burn Injuries. The New England Journal of Medicine, 338, 362-366. http://dx.doi.org/10.1056/NEJM199802053380604

[6] Coste, J., Wasserman, D. and Venot, A. (1996) Predicting Mortality in Adult Burned Patients: Methodological Aspects of the Construction and Validation of a Composite Ratio Scale. Journal of Clinical Epidemiology, 49, 1125-1131. http://dx.doi.org/10.1016/0895-4356(96)00197-7

[7] Saffle, J.R. (1998) Predicting Outcomes of Burns. The New England Journal of Medicine, 338, 387-388. http://dx.doi.org/10.1056/NEJM199802053380610

[8] Smith, D.L., Cairns, B.A., Ramadan, F., Dalston, J.S., Fakhry, S.M., Rutledge, R., Meyer, A.A. and Peterson, H.D. (1994) Effect of Inhalation Injury, Burn Size, and Age on Mortality: A Study of 1447 Consecutive Burn Patients. Journal of Trauma-Injury Infection \& Critical Care, 37, 655-659. http://dx.doi.org/10.1097/00005373-199410000-00021

[9] Muller, M.J. and Herndon, D.N. (1994) The Challenge of Burns. The Lancet, 343, 216-220. http://dx.doi.org/10.1016/S0140-6736(94)90995-4

[10] Vico, P. and Papillon, J. (1992) Factors Involved in Burn Mortality: A Multivariate Statistical Approach Based on Discriminant Analysis. Burns, 18, 212-215. http://dx.doi.org/10.1016/0305-4179(92)90071-2

[11] Benmeir, P., Sagi, A., Greber, B., Vardy, D., Lusthaus, S., Picard, E., et al. (1991) An Analysis of Mortality in Patients with Burns Covering 40 Percent BSA or More: A Retrospective Review Covering 24 Years (1964-88). Burns, 17, 402405. http://dx.doi.org/10.1016/S0305-4179(05)80075-0

[12] Ganesamoni, S., Kate, V. and Sadasivan, J. (2010) Epidemiology of Hospitalized Burn Patients in a Tertiary Care Hospital in South India. Burns, 36, 422-429. http://dx.doi.org/10.1016/j.burns.2009.06.212 
[13] Light, T.D., Latenser, B.A., Kealey, G.P., Wibbenmeyer, L.A., Rosenthal, G.E. and Sarrazin, M.V. (2009) The Effect of Burn Center and Burn Center Volume on the Mortality of Burned Adults-An Analysis of the Data in the National Burn Repository. Journal of Burn Care \& Research, 30, 776-782. http://dx.doi.org/10.1097/BCR.0b013e3181b47ed2

[14] Burton, K.R., Sharma, V.K., Harrop, R. and Lindsay, R. (2009) A Population-Based Study of the Epidemiology of Acute Adult Burn Injuries in the Calgary Health Region and Factors Associated with Mortality and Hospital Length of Stay from 1995 to 2004. Burns, 35, 572-579. http://dx.doi.org/10.1016/j.burns.2008.10.003

[15] Lundgren, R.S., Kramer, C.B., Rivara, F.P., Wang, J., Heimbach, D.M., Gibran, N.S., Klein, M.B., Burton, K.R., Sharma, V.K., Harrop, R. and Lindsay, R. (2009) Influence of Comorbidities and Age on Outcome Following Burn Injury in Older Adults. Journal of Burn Care \& Research, 30, 307-314. http://dx.doi.org/10.1097/BCR.0b013e318198a416

[16] Ince, H., Kandemir, E., Ince, N., Güloğlu, R. and Safran, N. (2008) Burn and Vital Risk Criteria in Industrial Accidents (as Forensic Medicine Approach). Ulusal travma ve acil cerrahi dergisi, 14, 145-148.

[17] Hilal, A., Cekin, N., Arslan, M. and Gulmen, M. (2008) Deaths Due to Burns in Adana, Turkey. Burns, 34, $982-985$.

[18] McGwin Jr., G., George, R.L., Cross, J.M. and Rue, L.W. (2008) Improving the Ability to Predict Mortality among Burn Patients. Burns, 34, 320-327. http://dx.doi.org/10.1016/j.burns.2007.06.003

[19] Macedo, J.L. and Santos, J.B. (2007) Predictive Factors of Mortality in Burn Patients. Revista do Instituto de Medicina Tropical de São Paulo, 49, 365-370. http://dx.doi.org/10.1590/S0036-46652007000600006

[20] Wolf, S.E., Rose, J.K., Desai, M.H., Barrow, R.E. and Herndon, D.N. (1997) Mortality Determinants in Massive Pediatric Burns: An Analysis of 103 Children with $\geq 80 \%$ TBSA Burns ( $\geq 70 \%$ Full Thickness). Annals of Surgery, 225, 554-565. http://dx.doi.org/10.1097/00000658-199705000-00012

[21] Light, T.D., Latenser, B.A., Heinle, J.A., Stolpen, M.S., Quinn, K.A., Ravindran, V. and Chacko, J. (2009) Demographics of Pediatric Burns in Vellore, India. Journal of Burn Care \& Research, 30, 50-54. http://dx.doi.org/10.1097/BCR.0b013e318191fc91

[22] Barrow, R.E., Spies, M., Barrow, L.N. and Herndon, D.N. (2004) Influence of Demographics and Inhalation Injury on Burn Mortality in Children. Burns, 30, 72-77. http://dx.doi.org/10.1016/j.burns.2003.07.003

[23] Morrow, S.E., Smith, D.L., Cairns, B.A., Howell, P.D., Nakayama, D.K. and Peterson, H.D. (1996) Etiology and Outcome of Pediatric Burns. Journal of Pediatric Surgery, 31, 329-333. http://dx.doi.org/10.1016/S0022-3468(96)90732-0

[24] Cuenca-Pardo, J., de Jesús Alvarez-Díaz, C. and Comprés-Pichardo, T.A. (2008) Related Factors in Burn Children. Epidemiological Study of the Burn Unit at the "Magdalena de las Salinas” Traumatology Hospital. Journal of Burn Care \& Research, 29, 468-474. http://dx.doi.org/10.1097/BCR.0b013e3181710857

[25] Spinks, A., Wasiak, J., Cleland, H., Beben, N. and Macpherson, A.K. (2008) Ten-Year Epidemiological Study of Pediatric Burns in Canada. Journal of Burn Care \& Research, 29, 482-488. http://dx.doi.org/10.1097/BCR.0b013e3181776ed9

[26] Spies, M., Herndon, D.N., Rosenblatt, J.I., Sanford, A.P. and Wolf, S.E. (2003) Prediction of Mortality from Catastrophic Burns in Children. Lancet, 361, 989-994. http://dx.doi.org/10.1016/S0140-6736(03)12824-3

[27] Toon, M.H., Maybauer, D.M., Arceneaux, L.L., Fraser, J.F., Meyer, W., Runge, A. and Maybauer, M.O. (2011) Children with Burn Injuries-Assessment of Trauma, Neglect, Violence and Abuse. Journal of Injury and Violence Research, 3, 99-111. http://dx.doi.org/10.5249/jivr.v3i2.91

[28] Thombs, B.D., Singh, V.A. and Milner, S.M. (2006) Children under 4 Years Are at Greater Risk of Mortality Following Acute Burn Injury: Evidence from a National Sample of 12,902 Pediatric Admissions. Shock, 26, 348-352. http://dx.doi.org/10.1097/01.shk.0000228170.94468.e1

[29] Barret, J.P., Jeschke, M.G. and Herndon, D.N. (2001) Fatty Infiltration of the Liver in Severely Burned Pediatric Patients: Autopsy Findings and Clinical Implications. Journal of Trauma, 51, 736-739. http://dx.doi.org/10.1097/00005373-200110000-00019

[30] Scholer, S.J., Hickson, G.B., Mitchel Jr., E.F. and Ray, W.A. (1998) Predictors of Mortality from Fires in Young Children. Pediatrics, 101, e12. http://dx.doi.org/10.1542/peds.101.5.e12

[31] Housinger, T.A., Brinkerhoff, C. and Warden, G.D. (1993) The Relationship between Platelet Count, Sepsis, and Survival in Pediatric Burn Patients. JAMA Surgery, 128, 65-67. http://dx.doi.org/10.1001/archsurg.1993.01420130073011

[32] Khorasani, E.N. and Mansouri, F. (2010) Effect of Early Enteral Nutrition on Morbidity and Mortality in Children with Burns. Burns, 36, 1067-1071. http://dx.doi.org/10.1016/j.burns.2009.12.005

[33] Osler, T., Glance, L.G. and Hosmer, D.W. (2010) Simplified Estimates of the Probability of Death after Burn Injuries: Extending and Updating the Baux Score. Journal of Trauma, 68, 690-697. http://dx.doi.org/10.1097/TA.0b013e3181c453b3 
Scientific Research Publishing (SCIRP) is one of the largest Open Access journal publishers. It is currently publishing more than 200 open access, online, peer-reviewed journals covering a wide range of academic disciplines. SCIRP serves the worldwide academic communities and contributes to the progress and application of science with its publication.

Other selected journals from SCIRP are listed as below. Submit your manuscript to us via either submit@scirp.org or Online Submission Portal.
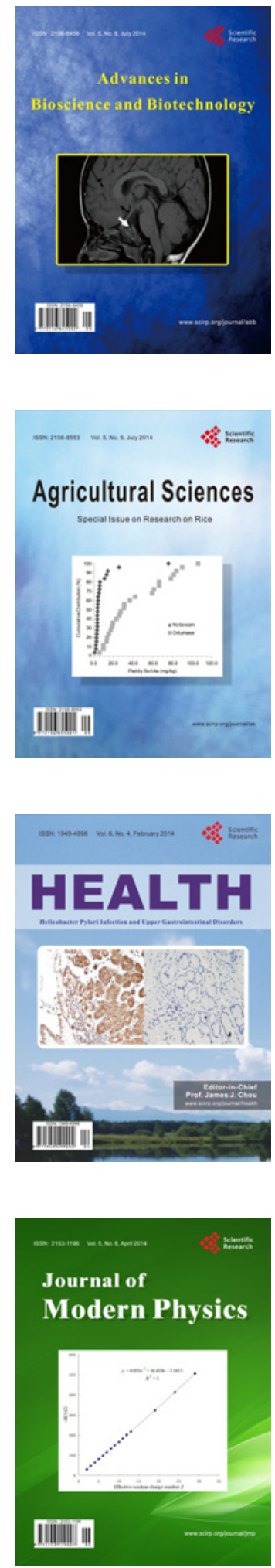
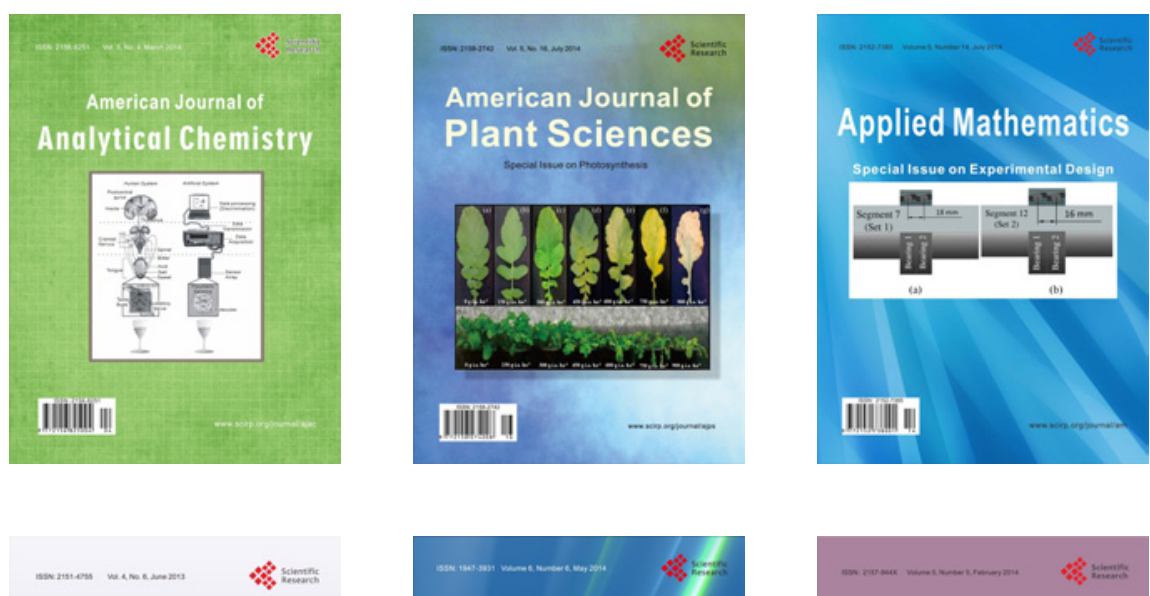

Creative Education
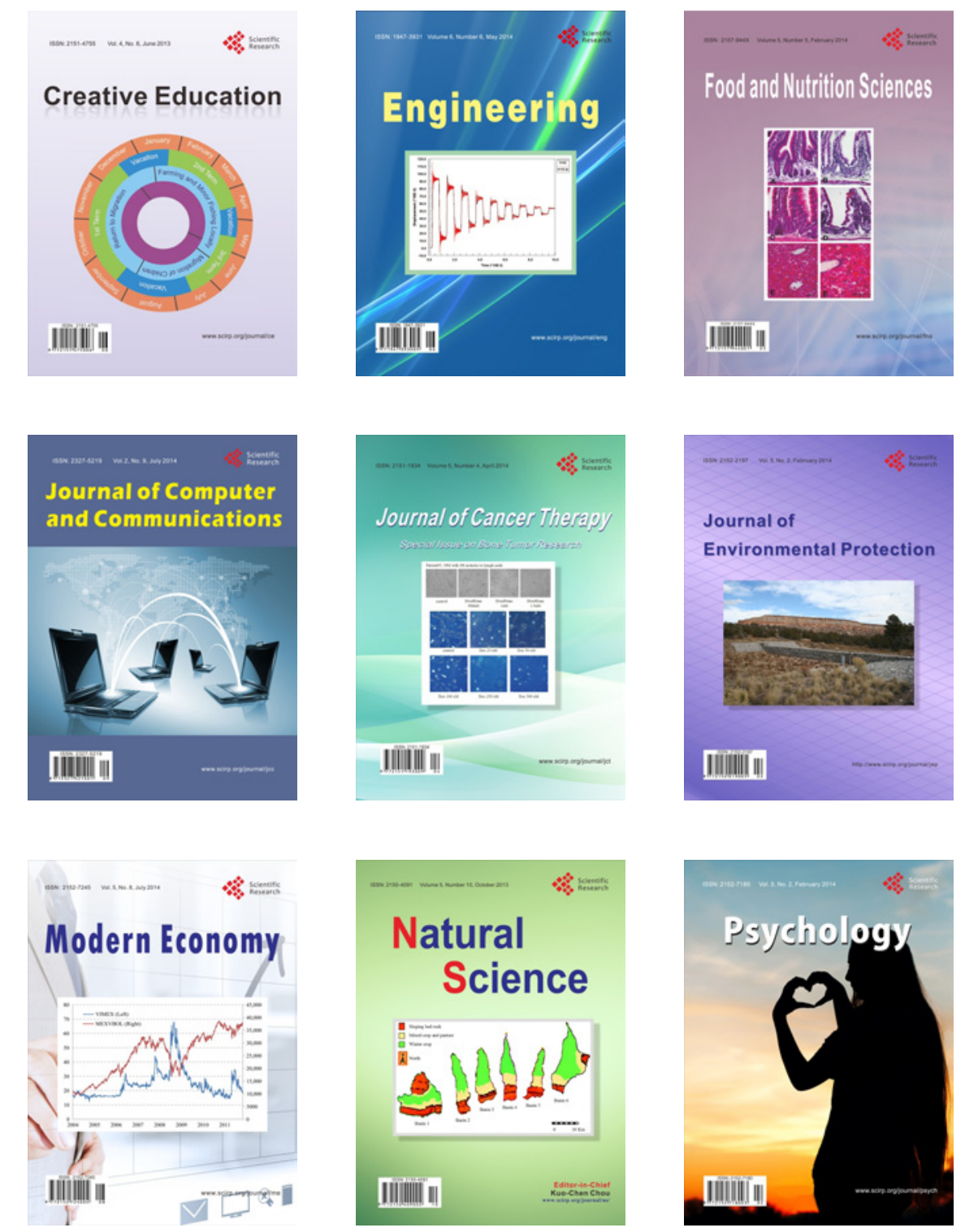